\title{
ENZYME INHIBITORY PROPERTIES OF ZERUMBONE
}

\author{
Shaymaa Fadhel Abbas Albaayit* \\ Department of Biology, College of Science, University of Baghdad, Baghdad, Iraq \\ *Corresponding author's e-mail: shaymaa_albaayit@yahoo.com
}

\begin{abstract}
Zerumbone (ZER) is a well-known sesquiterpene composite can be set up in the rhizomes of Zingiber zerumbet (Smith), having anti-cancer, anti-inflammatory and anti-hyperglycemic effects. This study aimed to investigate the inhibitory potential of ZER against drug-target enzymes involved in human pathologies, namely, obesity (Pancreatic lipase) and idiopathic intracranial hypertension (carbonic anhydrase). Result: ZER inhibits pancreatic lipase and carbonic anhydrase at percentages of 52.5 and $71.3 \%$ with $184.1 \pm 5$ and $69.3 \pm 0.43 \mu \mathrm{g} / \mathrm{mL} \mathrm{IC}_{50}$ values, respectively. Consequently, ZER has an excellent inhibitory action against pancreatic lipase and carbonic anhydrase, making it interesting anti-obesity drug candidate and avert pathophysiological-related carbonic anhydrase.
\end{abstract}

Keywords: Pancreatic lipase, carbonic anhydrase, zingiber zerumbet.

\section{INTRODUCTION}

Enzymes play very important role to biocatalyst the metabolism and have been interact with various substances taken in the body. Especially some enzymes are known as drug-target such as pancreatic lipase and carbonic anhydrase (Aslan et al., 2019).

Obesity is a state in which there is excessive accumulation of fats in the body due to less energy expenditure as compared to high energy intake. It has increased in almost all countries and record approximately 1.9 billion people overweight throughout the world (Wang et al., 2020). Obesity is associated with serious fitness harms like metabolic, hormonal, and cardiac ailments (Jaradat et al., 2017). Recently, pancreatic lipase inhibitors have gained much attention as an ideal mechanism for treating obesity due to the fact that pancreatic lipase is responsible for breaking down fats for further absorption. Since, pancreatic lipase will be inhibited by compounds therefore dietary fats will not be broken down and will not be absorbed by the intestine. Due to this fact, many researchers are interested on searching potent natural compounds which possess anti-pancreatic lipase activity (Ong et al., 2016).

Carbonic anhydrases (CA) is responsible for many physiological processes, including respiration, carbon dioxide and bicarbonate transport, $\mathrm{pH}$ and $\mathrm{CO} 2$ balance in the lungs and metabolizing tissues (Kaya et al., 2019). Carbonic anhydrases are necessary also involved in the biological /patho-physiological processes, such as tumorigenicity, gluconeogenesis, neurological disorders, and obesity, as well as gastric and duodenal ulcers (Ashiq et al., 2017). Therefore, there is need of potent compounds from natural sources which could act as safe CA inhibitors and consider as first line treatments for these diseases.

Plant-derived bioactive compounds are well flourished for their therapeutic actions in the prevention and treatment of various diseases. Zerumbone is a major compound derived from the rhizomes of Zingiber zerumbet (Smith) that has been traditionally used for the treatment of diarrhea, stomach ulcer, headache and asthma (Albaayit et al., 2021a; Attyah and Ismail, 2013). Several pharmacological properties of ZER have been reported including antinociceptive, antimicrobial, immunomodulation effect, anti-inflammatory and anticancer towards several cancer cell lines (Albaayit et al., 2020a; Albaayit and Maharjan, 2018). However, no scientific evidence toward enzyme inhibition against pancreatic lipase and carbonic anhydrase has been reported during our literature survey. Thus, this study was carried to evaluate the pancreatic lipase and carbonic anhydrase inhibition potential of ZER which could lead to control the effects of obesity, glaucoma cancer, and neurological disorders.

\section{MATERIALS AND METHODS}

The tested plant material having crystals of creamy white colored was obtained from Professor Dr. Rasedee Abdullah, Universiti Putra Malaysia (UPM). The crystallization of the plant material was done three times to attain unadulterated crystals of zerumbone and retained at $4{ }^{\circ} \mathrm{C}$ till further usage.

In vitro Pancreatic Lipase inhibition: The lipase inhibition assay was carried out spectrophotometrically in 96-well plate using Tris-HCl buffer as described by Ong et al. (2016). The reaction mixture contained various concentrations of ZER (0.2-0.025 mg/mL), PPL (200 units $/ \mathrm{mL}$ ) and $p$-nitrophenyl 
butyrate (pNPB) substrate solution (10 $\mathrm{mM}$ in acetonitrile). After incubation at $37 \mathrm{oC}$ for $5 \mathrm{~min}$, the absorbance of the released PPL was measured at $410 \mathrm{~nm}$ ELISA plate reader (Spectra Max M2, Molecular Devices, CA, USA). The percentage inhibition of enzyme had been used to analysis data from which $\mathrm{IC}_{50}$ values were calculated.

$\%$ inhibitory activity of enzyme

$$
=100-\frac{\text { O.D of enzyme with inhibitor }}{\text { O.D of enzyme without inhibitor }} \times 100
$$

Carbonic anhydrase inhibition assay: Reaction mixture of $200 \mu \mathrm{L}$ included $20 \mu \mathrm{L}$ of ZER $(0.1-0.0125 \mathrm{mg} / \mathrm{mL})$ in DMSO, $140 \mu \mathrm{L}$ of the HEPES-tris buffer (20 mM at pH 7.4), $20 \mu \mathrm{L}$ of enzyme CA $(0.1 \mathrm{mg} / \mathrm{mL})$ prepared in buffer, and 20 $\mu \mathrm{L}$ of a solution of 4-nitrophenyl acetate, incubated for fifteen minutes in a 96-well broad-plate. $20 \mu \mathrm{L}(0.7 \mathrm{mM})$ of 4 nitrophenyl acetate (4-NPA) substrate was added, and change in absorbance was observed for thirty minutes min by steady breaks of one min, by means of microplate readers (Tecan, California, USA) (Kaya et al., 2019). The enzyme inhibition was expressed as $\mathrm{IC}_{50}$ (concentration of ZER that reduces the enzyme activity by $50 \%$ ) value.

\section{RESULT AND DISCUSSION}

Since ancient time, mankind had been using different plants to treat various diseases; thus, collected knowledge has advanced the ethnomedicine area due to which many researchers are doing research in this field to find good candidate drugs (Albaayit, 2021; Albaayit et al., 2021b; Albaayit et al., 2021c; Albaayit et al., 2020b; Al-Bahrani et al., 2020; Albaayit et al., 2019; Al-Ani et al., 2018). Zerumbone is the most active compound from edible ginger Zingiber zerumbet has therapeutic efficacy against various types of diseases (Albaayit and Maharjan, 2018; Albaayit et al., 2021d). As a development to that reviews, interestingly, the current review expect to investigate on the inhibition impacts of ZER against pancreatic lipase and carbonic anhydrase that may be considered as a potential therapeutic to prevent obesity, cancer, and neurodegenerative diseases.

Recently, anti-obesity researchers are trying to focus on the natural sources, particularly those that named conventional restorative and palatable sorts for the treatment of stoutness and for controlling of overweight because of their wellbeing issue. The significance of pancreatic lipase inhibition assay has increased because of their possible adequacy of regular items as against stoutness therapy. Pancreatic lipase assumes a key part in dietary triacylglycerol assimilation, hydrolyzing triacylglycerol to 2-monoacylglycerol and unsaturated fats. It is notable that dietary fat isn't straightforwardly consumed from the digestive tract except if it has been exposed to the activity of pancreatic lipase (Ado et al., 2013).

Indeed, carbonic anhydrase considers ubiquitous in a variety of tissues, being involved in the reversible hydration of carbon dioxide to bicarbonate with the release of protons
(Sahin et al., 2011). Therefore, imbalances levels of this enzyme have been associated with many diseases such as obesity, cancer, epilepsy, glaucoma, gastroduodenal ulcers, and neurodegenerative (Iqbal et al., 2015).

From the outcome of present study, it is concluded that ZER showed enzyme inhibitory activity of 52.5 and $71.3 \%$ at high concentration, with $\mathrm{IC}_{50}$ value of $184.1 \pm 5$ and $69.3 \pm 0.43$ $\mu \mathrm{g} / \mathrm{mL}$ against pancreatic lipase and carbonic anhydrase, respectively (fig.1). The finding is in agreement with previous study by Arya et al. (2021), who reported that sesquiterpene has potential inhibitors of enzymes by binding to the substrate target of enzyme, preventing the hydrolysis of corresponding substrate.
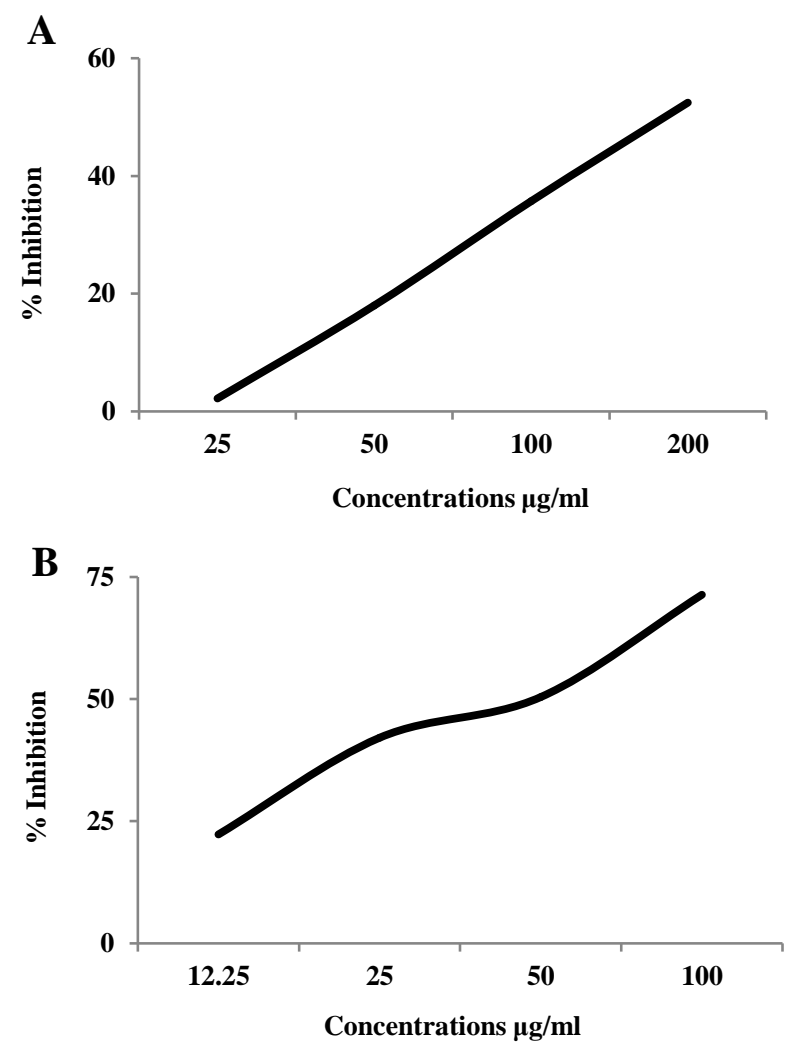

Figure 1.Enzyme inhibition percentage of pancreatic lipase (A) and Carbonic anhydrase (B) after treating with zerumbone.

Conclusion: Zerumbone showed inhibition against pancreatic lipase and carbonic anhydrase enzyme, thus, in terms of safety and efficacy, this compound possess capacity to be used for the treatment of obesity, cancer, and neurodegenerative diseases.

Acknowledgment: The author is gratitude to Prof. Dr. M. Iqbal Choudhary for providing NAM-ICCBS fellowship, in International Center for Chemical and Biological Sciences, University of Karachi, Karachi, Pakistan. 


\section{REFERENCES}

Luo, Y. and D.L. Rimmer. 1995. Zinc-copper interaction affecting plant growth on a metal-contaminated soil. Environ. Pollut. 88:79-83.

Ado, M. A., F. Abas, A.S. Mohammed and H.M. Ghazali. 2013. Anti-and pro-lipase activity of selected medicinal, herbal and aquatic plants, and structure elucidation of an anti-lipase compound. Molecules. 18:14651-14669.

Al-Ani, L.K.T., M.I. Yonus, B.A. Mahdii, M.A. Omer, J.K. Taher, S.F.A Albaayit and S.B. Al-Khoja. 2018. First record of use Fusarium proliferatum fungi in direct treatment to control the adult of wheat flour Tribolium confusum, as well as, use the entomopathogenic fungi Beauveria bassiana. Ecol. Environ. Conserv. 24:29-34.

Albaayit, S.F.A. 2021. Evaluation of anti-methicillin resistant Staphylococcus aureus property of Clausena excavata leaves by using atomic force microscopy and flowcytometry techniques. Pak J Agri Sci. 58:315-320.

Albaayit, S.F.A. and R. Maharjan. 2018. Immunomodulation of Zerumbone via Decreasing the Production of Reactive Oxygen Species from Immune Cells. Pak J Biol Sci. 9:475-479.

Albaayit S.F.A, R. Maharjan, and M. Khan. 2021a. Evaluation of hemolysis activity of Zerumbone on RBCs and brine shrimp toxicity. Baghdad Sci. J. 18:6569.

Albaayit, S.F.A., A. Rasedee and N. Abdullah. 2020a. Zerumbone-loaded nanostructured lipid carrier gel facilitates wound healing in rats. Rev Bras Farmacogn. 30:272-278.

Albaayit, S.F.A., A.S.K. Al-Khafaji and H.S. Alnaimy. 2019. In vitro macrophage nitric oxide and interleukin-1 beta suppression by Moringa peregrina seed. Turkish J. Pharm. Sci.16:362.

Albaayit, S.F.A., R. Maharjan, R. Abdullah and M.H.M. Noor. 2021b. Anti-Enterococcus Faecalis, Cytotoxicity, Phytotoxicity, and Anticancer Studies on Clausena excavata Burum. f. (Rutaceae) Leaves. BioMed Research International, 2021.

Albaayit, S. F. A., A. Rasedee, N. Abdullah and Y. Abba. 2020b. Methanolic extract of Clausena excavata promotes wound healing via antiinflammatory and antiapoptotic activities. Asian Pac. J. Trop. Biomed. 10:232232.

Albaayit, S.F.A., M. Khan, R. Abdullah and M. H. M. Noor. 2021c. Ethyl acetate extract of Clausena excavata induces growth inhibition of non-small-lung cancer, NCI-H460, cell line via apoptosis. J. Appl. Biomed. 19: 40-47.
Albaayit, S.F.A., M. Khan and R. Abdullah. 2021d. Zerumbone induces growth inhibition of Burkitt's lymphoma cell line via apoptosis. Natural Volatiles and Essential Oils. 8:56-63.

Al-Bahrani, R.M., H.M. Radif, and S.F.A. Albaayit. 2020. Evaluation of potent silver nanoparticles production from Agaricus bisporus against Helicobacter pylori. Pak J Agri Sci.57:1197-1201.

Attyah, A.M. and S.H. Ismail. 2012. Protective Effect of Ginger Extract Against Cisplatin-Induced Hepatotoxicity and Cardiotoxicity in Rats. Iraqi J. Pharm. Sci. 21: 27-33.

Arya, A., R. Chahal, R. Rao, M. Rahman, D. Kaushik, M.F. Akhtar and V. Mittal. 2021. Acetylcholinesterase Inhibitory Potential of Various Sesquiterpene Analogues for Alzheimer's Disease Therapy. Biomolecules. 11: 350 .

Ashiq, U., R.A. Jamal, M. Saleem and M. Mahroof-Tahir. 2017. Alpha-glucosidase and carbonic anhydrase inhibition studies of Pd (II)-hydrazide complexes. Arabian Journal of Chemistry. 10:488-499.

Aslan, H.E., Y. Demir, M.S. Özaslan, F. Türkan, S. Beydemir and O.I. Küfrevioğlu. 2019. The behavior of some chalcones on acetylcholinesterase and carbonic anhydrase activity. Drug Chem. Toxicol. 42:634-640.

Iqbal, J., M. Al-Rashida, S. Durdagi, V. Alterio and A. Di Fiore. 2015. Recent developments of carbonic anhydrase inhibitors as potential drugs.

Jaradat, N., A.N. Zaid, F. Hussein, M. Zaqzouq, H. Aljammal and O. Ayesh. 2017. Anti-lipase potential of the organic and aqueous extracts of ten traditional edible and medicinal plants in Palestine; a comparison study with orlistat. Medicines. 4:89.

Kaya, E.D., B. Erğun, Y. Demir, A.L.I.M. Zuhal and S. Beydemir. 2019. The in vitro impacts of some plant extracts on carbonic anhydrase i, ii and paraoxonase1. Hacettepe J. Biol. Chem. 47:51-59.

Ong, S.L., S.H. Mah and H.Y. Lai. 2016. Porcine pancreatic lipase inhibitory agent isolated from medicinal herb and inhibition kinetics of extracts from Eleusine indica (L.) Gaertner. J.pharmac. 2016:1-9.

Sahin, H., R. Aliyazicioglu, O. Yildiz, S. Kolayli, A. Innocenti, A and C.T. Supuran. 2011. Honey, polen, and propolis extracts show potent inhibitory activity against the zinc metalloenzyme carbonic anhydrase. J. Enzyme Inhib Med Chem. 26:440-444.

Wang, S., L. Chen, H. Yang, J. Gu, J. Wang and F. Ren. 2020. Regular intake of white kidney beans extract (Phaseolus vulgaris L.) induces weight loss compared to placebo in obese human subjects. Food Sci. Nutr. 8:1315-1324.

[Received 31 Jan 2021; Accepted 03 Jun. 2021; Published (online) 25 Jun 2021] 